\title{
Case Report: Thrombotic Thrombocytopenic Purpura Following Honeybee Envenomation: A Case Report
}

\author{
Zahra Khalighi $^{1}$ (D), Golnaz Azami², Elham Shafiei ${ }^{3}$, Ali Sahebi ${ }^{3}$, Aliashraf Mozafari $^{4 *}$ (D) \\ 1. Department of Internal Medicine, School of Medicine, Ilam University of Medical Sciences, Ilam, Iran. \\ 2. Department of Nursing and Midwifery, School of Nursing and Midwifery, Ilam University of Medical Sciences, Ilam, Iran \\ 3. Clinical Research Development Unit, Shahid Mostafa Khomeini Hospital, Ilam University of Medical Sciences, Ilam, Iran. \\ 4. Department of Epidemiology and Biostatistics, Tehran University of Medical Science, Tehran, Iran.
}

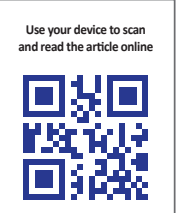

Citation: Khalighi Z, Azami G, Shafiei E, Sahebi A, Mozafari A. Thrombotic Thrombocytopenic Purpura Following Honeybee Envenomation: A Case Report. International Journal of Medical Toxicology and Forensic Medicine. 2020; 10(2):28794. https://doi.org/10.32598/ijmtfm.v10i2.28794

https://doi.org/10.32598/ijmtfm.v10i2.28794

\section{(c) (1) (\$)}

Article info:

Received: 25 Jan 2020

First Revision: 27 Jan 2020

Accepted: 05 Feb 2020

Published: 23 Jun 2020

\section{Keywords:}

Thrombotic Thrombocytopenic Purpura (TTP), Honey bee sting, Anaphylactic shock

\section{A BSTRACT}

Background: Thrombotic Thrombocytopenic Purpura (TTP) is a rare and life-threatening disorder characterized by severe thrombocytopenia, microangiopathic hemolytic anemia, fever, renal dysfunction, and neurological deficient. TTP leads to the formation of blood clots in small blood vessels throughout the body. TTP is associated with many risk factors such as pregnancy, HIV, cancer, lupus, and infections. Recently there have been few published case reports of bee sting associated TTP.

Methods: A 67-year-old man from a rural area of the Southwest Province of Iran, Ilam, was referred to the academic general hospital because of fever, chills, sweating, vomiting and dizziness following the honeybee sting on his body.

Results: this study showed that,multiple co-morbidities including CVD and diabetes, along with coagulation abnormalities after honeybee stings, seriously exacerbated patient hemodynamic status.

Conclusion: TTP, as a major complication due to the toxic reaction of a large number of bee stings with underlying diseases in patients, should be given more attention.

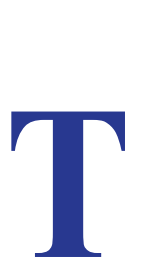

\section{Introduction}

hrombotic Thrombocytopenic Purpura (TTP) is a rare blood disorder characterized by thrombocytopenia, microangiopathic hemolytic anemia, impaired neurological state, renal dysfunction, and fever [1]. Many different factors are associated with TTP, including drugs, infections, toxins, systemic lupus erythematosus, lymph proliferative disorders, hereditary thrombocytopenia, malignancy, and platelet aggregation disorders. Although the exact pathophysiology of TTP is still unclear, several lines of clinical and basic science observation suggest than the abnormal function of the von Willebrand factor is involved [1-3]. TTP is caused by severe ADAMTS13 activity deficiency and a lack of von Willebrand factor-cleaving protease. Disruption of ADAMTS13 activity leads to an accumulation of large uncleaved multimers of von Willebrand factor, which in turn causes inappropriate platelet aggregation and en-

* Corresponding Author:

Aliashraf Mozafari, PhD.

Address: Department of Epidemiology and Biostatistics, Tehran University of Medical Science, Tehran, Iran.

Tel: +98 (918) 3432983

E-mail: amozafari99@yahoo.com 
dothelial damage [4]. The consumption of platelets into these micro-thrombi causes severe thrombocytopenia, tissue ischemia, and organ dysfunction. This condition can commonly involve the brain, heart, and kidney, and potentially resulting in acute thrombolytic events such as stroke, myocardial infarction, venous thrombosis, and early death [5]. We report a case of a 67-year-old man who presented to the emergency department with TTP after the bee sting.

\section{Case Presentation}

A 67-year-old man living in a rural area of Ilam province, Iran presented to the emergency department of a governmental teaching hospital with 2 days history of vomiting, fever, chills, sweats, and dizziness. The patient had a history of eating mushroom 10 days earlier. He also revealed a history of more than 20 honeybee stings 3 days ago. The medical history revealed that he had type 2 diabetes, hypertension, and myocardial infarction. The patient had ventricular aneurysm confirmed by angiography. He underwent open-heart surgery in 2010. Subsequently, oral warfarin therapy was started.

On admission, the patient was awake and alert but unable to communicate properly. The patient had a fever, chills, sweats, nausea with projectile vomiting, dysarthria, conjugate gaze palsy, and rhythmic movements of the hands. The patient was treated with ondansetron 2 $\mathrm{mg} / \mathrm{dL}$ intravenously.

On physical examination, his vital signs were $\mathrm{BP}=160 / 11 \mathrm{~mm} \mathrm{Hg}, \mathrm{PR}=78$ beats $/ \mathrm{m}, \mathrm{RR}=17$ breaths $/ \mathrm{m}$ $\mathrm{T}=37.5^{\circ} \mathrm{C}, \mathrm{SpO} 2=95 \%$ in room air. Table 1 presents the first results of the blood and urine sample. Laboratory tests revealed severe thrombocytopenia $(<46000)$, a significant increase in BUN (83 mg/dL), Cr $(2.01 \mathrm{mg} /$ $\mathrm{dL})$, and BS (153 mg/dL). The tissue and organ damage resulting from the ischemia leads to increased levels of lactate dehydrogenase $(\mathrm{LDH}=2255 \mathrm{U} / \mathrm{L})$ and creatinine. Elevated levels of creatinine are usually an indication of renal involvement. The hemoglobin level was normal at $13.4 \mathrm{mg} / \mathrm{dL}$. The chest X-ray and thoracic CT scan findings were normal. Echocardiographic examination indicated low ejection fraction (EF 25\%-30\%) with mild to moderate mitral valve regurgitation.

The patient was admitted to the neurology service. He was also evaluated by physicians from the departments of general internal medicine, cardiology, infectious diseases, nephrology, pathology, and hematology. The doctors decided to immediately transfer him to the adult Intensive Care Unit (ICU). The patient was treated with clindamycin, $600 \mathrm{mg}$ three times daily, and ceftriaxone $1 \mathrm{~g}$ two times daily. The patient experience loss of consciousness 24 hours after admission to ICU, so endotracheal

Table 1. Biochemical tests of the patient with thrombotic thrombocytopenic purpura

\begin{tabular}{|c|c|c|}
\hline Laboratory Result & Normal Range & Result \\
\hline BS & $70-115 \mathrm{mg} / \mathrm{dL}$ & $153 \mathrm{mg} / \mathrm{dL}$ \\
\hline BUN & $15-45 \mathrm{mg} / \mathrm{dL}$ & 83 mg/dL \\
\hline $\mathrm{Cr}$ & $0.8-1.5 \mathrm{mg} / \mathrm{dL}$ & $2.01 \mathrm{mg} / \mathrm{dL}$ \\
\hline Bilirubin. Total & $0.3-1.2 \mathrm{mg} / \mathrm{dL}$ & $3.96 \mathrm{mg} / \mathrm{dL}$ \\
\hline LDH & $230-460 \mathrm{U} / \mathrm{L}$ & $2255 U / L$ \\
\hline $\mathrm{HB}$ & $12-17 \mathrm{~g} / \mathrm{dL}$ & $13.4 \mathrm{~g} / \mathrm{dL}$ \\
\hline $\mathrm{HCT}$ & $36 \%-53 \%$ & $39.7 \%$ \\
\hline WBC & 4000-10000 UI & 13500 UI \\
\hline PLT & 150.000-450.000 UI & 46000 UI \\
\hline PT & $11-13.5 \mathrm{~s}$ & $21 \mathrm{~s}$ \\
\hline PTT & $60-70 \mathrm{~s}$ & $30 \mathrm{~s}$ \\
\hline INR & $0.8-1.1$ & 2.2 \\
\hline $\mathrm{Na}$ & $135-145$ & 142 \\
\hline $\mathrm{K}$ & $3.5-5.5$ & 4.5 \\
\hline CK-MB & 0-25 UI/I & 33 UI/I \\
\hline Troponin & - & Negative \\
\hline UA/RBC & - & $10-12$ \\
\hline
\end{tabular}


intubation and mechanical ventilation were initiated. His $\mathrm{pH}$ level decreased $(\mathrm{pH}=6.88)$, and serum creatinine increased further in the first 24 hours of ICU stay.

The clinical findings in the presence of a significant decrease in the platelet count (23000) led the physician to the diagnosis of TTP. The patient required fresh frozen plasma (FFP) transfusion due to decreased platelet count with increased LDH. A left subclavian catheter was inserted, and the patient was dialyzed without heparin. The patient developed severe prolonged hypotension (systolic $\mathrm{BP}<80 \mathrm{~mm} \mathrm{Hg}$ ) during the plasmapheresis and required a temporary stoppage of the exchange and administration of FFP. Hypotension was treated with feet elevation and intravenous norepinephrine. Because the patient's clinical state immediately deteriorate, he was observed closely. The continuing consumption of platelets and coagulation factors may cause severe tissue damage commonly involving heart and kidney, resulting in acute myocardial infarction and death. After the second hospital day, he developed cardiopulmonary arrest and died.

\section{Discussion}

Moschcowitz initially described TTP in 1924 [6]. It is characterized by increased microvascular platelet clumping resulting in thrombocytopenia and microangiopathic hemolytic anemia [1]. TTP is often accompanied by multiple organ dysfunction, renal failure, neurological abnormalities, and fever [7]. A large variety of unusual reactions and clinical manifestations have been reported following hymenoptera stings, including serum sickness neurological disorders, delayed hypersensitivity reaction 1 , and renal disease [8]. To date, few cases of TTP after honeybee sting have been reported. Our patient experienced serum sickness without clinical evidence of TTP that occurred after a honeybee sting. Serum sickness occurs within 3 days to 2 weeks after envenomation. This condition can induce the formation of circulating immune complexes, which in turn lead to TTP and disseminated intravascular coagulation. TTP is a rare secondary complication that may occur after massive envenomation from honeybees. The specific sign of honeybee envenomation appeared to be related to the number of bee stings and patient inflammatory responses $[9,10]$.

A significant decrease in platelet count, together with elevated LDH levels, is an indicator of poor survival [5]. Besides, elderly patients with multiple comorbidities are more likely to develop severe complications [9]. This is unique among other reported cases where the patient was elderly with multiple comorbidities. Since older people commonly have multiple comorbidities, knowledge about which conditions contribute to an increased risk of tissue injury would be valuable. The patient had a history of open-heart surgery, hypertension, and type 2 diabetes. Fluctuation in blood pressure in the setting of diabetes and cardiovascular disease appear to worsen the side effects of honeybee envenomation. Our patient had a history of more than 20 honeybee stings 3 days ago.

Among the various causes of acquired TTP, honeybee envenomation is rarely reported. We present a 67-yearold man with TTP following honeybee envenomation. He developed signs of TTP, including fever, low platelet, increased LDH levels, impaired neurological state, and renal function. Advanced effects include a further decrease in platelet count and renal function. About 24 hours after hospitalization, the patient developed severe hypotension with acidosis. Severe hypotension leads to a temporary stoppage of FFP administration. After the second hospital day, unfortunately, our patient developed cardiopulmonary arrest and died. The continuing consumption of platelets and coagulation factors resulted in cardiopulmonary arrest and death. We are presenting this case to raise awareness about TTP following honeybee sting as it would have significant implications on mortality, treatment, and clinical courses.

\section{Conclusion}

For successful TTP treatment, raising awareness about disease treatment, prevention, and control in high-risk patients is essential. We presented a rare case to increase awareness among physicians as they consider TTP as a differential diagnosis following bee envenomation. Accurate treatment of TTP following honeybee sting has a significant impact on planning the optimal primary treatment modality.

\section{Ethical Considerations}

\section{Compliance with ethical guidelines}

The study protocol was in conformity with the ethical guidelines of the 1975 Declaration of Helsinki, revised in 1983. Private information, including name and surname was removed from the data sheet to comply with ethical concerns.

\section{Funding}

This study did not receive any specific grant from funding agencies in the public, commercial, or not-for profit sectors. 


\section{Author's contributions}

All authors contributed in preparing this article.

\section{Conflict of interest}

The authors declared no conflict of interest.

\section{Acknowledgements}

The authors would like to thank the staff of the Clinical Research Development Unit of Shahid Mostafa Khomeini Hospital, Ilam University of Medical Sciences for their cooperation with the project and providing the files.

\section{Reference}

[1] Ashley JR, Otero H, Aboulafia DM. Bee envenomation: A rare cause of thrombotic thrombocytopenic purpura. South Med J. 2003; 96(6):588-91. [DOI:10.1097/01. SMJ.0000051056.23320.09] [PMID]

[2] Withana M, Rodrigo C, Gnanathasan A, Gooneratne L. Presumptive thrombotic thrombocytopenic purpura following a hump-nosed viper (Hypnale hypnale) bite: A case report. J Venom Anim Toxins Incl Trop Dis. 2014. 20(1):26 [DOI:10.1186/1678-9199-20-26] [PMID] [PMCID]

[3] Bailey M, Maestas T, Betancourt R, Mikhael D, Babiker HM. A rare cause of Thrombotic Thrombocytopenia Purpura(TTP-) like syndrome, vitamin B12 deficiency: Interpretation of significant pathological findings. Case Rep Hematol. 2019; 2019:1529306.. [DOI:10.1155/2019/1529306] [PMID] [PMCID]

[4] Jen KY, Laszik ZG, EndotheLiopathies: Hemolytic uremic syndrome, thrombotic thrombocytopenic purpura, and preeclampsia, Pathobiol Hum Dis. 2014; 2767-87. [DOI:10.1016/ B978-0-12-386456-7.05406-X]

[5] Scully M, Cataland S, Peyvandi F. Undrestanding TTP [Internet]. 2020 [cited 2020 Jan 16]. Available from: https:// www.understandingttp.com/hcp/about-ttp/.

[6] Moschcowitz, E. Hyaline thrombosis of the terminal arterioles and capillaries: a hitherto undescribed disease. Thromb Haemost. 1978; 40(1):4-8. [PMID]

[7] Murthy PR, Ajith Karanth AK, Karanth S, Kalashetty M., Thrombotic thrombocytopenic purpura in a patient with snake bite. Indian J Case Reports. 2019. 5(3):277-9. [DOI:10.32677/IJCR.2019.v05.i03.028]

[8] Light WC, Robert MD, Reisman E, Masatoshi Shimizu MD, Carl E, Arbesman MD, et al. Unusual reactions following insect stings: clinical features and immunologic analysis. J Allergy Clin Immunol. 1977. 59(5):391-7. [DOI:10.1016/0091-6749(77)90024-0]

[9] Stack K. Pryor L. Significant traumatic intracranial hemorrhage in the setting of massive bee venom-induced coagulopathy: A case report. Wilderness Environ Med. 2016. 27(3):4058. [DOI:10.1016/j.wem.2016.05.005] [PMID]
[10] Namdev R, Dutta SR, Singh H. Acute immune thrombocytopenic purpura triggered by insect bite. J Indian Soc Pedod Prev Dent. 2009; 27(1):58. [DOI:10.4103/0970-4388.50821] [PMID] 